\title{
Article \\ Engineering of Vaginal Lactobacilli to Express Fluorescent Proteins Enables the Analysis of Their Mixture in Nanofibers
}

\author{
Spase Stojanov ${ }^{1,2}$, Tina Vida Plavec ${ }^{1,2}$, Julijana Kristl ${ }^{2}\left(\mathbb{D}\right.$, Špela Zupančič ${ }^{2}$ and Aleš Berlec ${ }^{1,2, *}$ (i) \\ 1 Department of Biotechnology, Jožef Stefan Institute, SI-1000 Ljubljana, Slovenia; spase.stojanov@ijs.si (S.S.); \\ tina.plavec@ijs.si (T.V.P.) \\ 2 Faculty of Pharmacy, University of Ljubljana, SI-1000 Ljubljana, Slovenia; julijana.kristl@ffa.uni-lj.si (J.K.); \\ spela.zupancic@ffa.uni-lj.si (Š.Z.) \\ * Correspondence: ales.berlec@ijs.si
}

check for

updates

Citation: Stojanov, S.; Plavec, T.V.; Kristl, J.; Zupančič, Š.; Berlec, A. Engineering of Vaginal Lactobacilli to Express Fluorescent Proteins Enables the Analysis of Their Mixture in Nanofibers. Int. J. Mol. Sci. 2021, 22, 13631. https://doi.org/10.3390/ ijms222413631

Academic Editor: Raghvendra Singh Yadav

Received: 1 December 2021

Accepted: 17 December 2021

Published: 20 December 2021

Publisher's Note: MDPI stays neutral with regard to jurisdictional claims in published maps and institutional affiliations.

Copyright: (c) 2021 by the authors. Licensee MDPI, Basel, Switzerland. This article is an open access article distributed under the terms and conditions of the Creative Commons Attribution (CC BY) license (https:// creativecommons.org/licenses/by/ $4.0 /)$.

\begin{abstract}
Lactobacilli are a promising natural tool against vaginal dysbiosis and infections. However, new local delivery systems and additional knowledge about their distribution and mechanism of action would contribute to the development of effective medicine. This will be facilitated by the introduction of the techniques for effective, inexpensive, and real-time tracking of these probiotics following their release. Here, we engineered three model vaginal lactobacilli (Lactobacillus crispatus ATCC 33820, Lactobacillus gasseri ATCC 33323, and Lactobacillus jensenii ATCC 25258) and a control Lactobacillus plantarum ATCC 8014 to express fluorescent proteins with different spectral properties, including infrared fluorescent protein (IRFP), green fluorescent protein (GFP), red fluorescent protein (mCherry), and blue fluorescent protein (mTagBFP2). The expression of these fluorescent proteins differed between the Lactobacillus species and enabled quantification and discrimination between lactobacilli, with the longer wavelength fluorescent proteins showing superior resolving power. Each Lactobacillus strain was labeled with an individual fluorescent protein and incorporated into poly (ethylene oxide) nanofibers using electrospinning, as confirmed by fluorescence and scanning electron microscopy. The lactobacilli retained their fluorescence in nanofibers, as well as after nanofiber dissolution. To summarize, vaginal lactobacilli were incorporated into electrospun nanofibers to provide a potential solid vaginal delivery system, and the fluorescent proteins were introduced to distinguish between them and allow their tracking in the future probiotic-delivery studies.
\end{abstract}

Keywords: lactobacilli; vaginal probiotics; fluorescent proteins; electrospinning; nanofibers; probiotic analysis; probiotic delivery

\section{Introduction}

The healthy human vagina is home to around 50 microbial species, of which the most dominating are bacteria from the genus Lactobacillus [1]. The main ones found are Lactobacillus crispatus, Lactobacillus jensenii, Lactobacillus gasseri, and Lactobacillus iners. Each of these is dominant in its community type, and L. crispatus is the most abundant [2]. Vaginal infections are favored by dysbiosis of the normal vaginal microbiota, whereby the numbers of lactobacilli decrease. This can allow the overgrowth of several opportunistic pathogens, including Gardnerella vaginalis, Atopobium vaginae, and Candida albicans [3].

Antimicrobial drugs are the first line of defense against bacterial infections. However, their frequent use can lead to antimicrobial resistance and also to high infection recurrence rates (i.e., $\sim 50 \%$ ) [3]. These high recurrence rates appear to be associated with the nonselective mechanisms of the antimicrobial drugs, where as well as the pathogens, the normal lactobacilli are also reduced $[4,5]$. Therefore, new therapeutic strategies are required to normalize vaginal dysbiosis. Re-establishing the vaginal microbial balance with Lactobacillus bacteria as probiotics can then prevent the overgrowth of vaginal pathogens and thus prevent recurrence of the vaginal infection. The dominant vaginal species, L. crispatus, has been shown to be active against vaginal pathogens, both alone and in combination 
with other lactobacilli [6-11]. Antimicrobial properties of other vaginal lactobacilli against vaginal and uropathogens have also been reported [12-15].

Despite the beneficial properties of vaginal lactobacilli, their application as probiotics is limited by the lack of an appropriate delivery system and their low viability and high sensitivity to environmental factors [16]. The currently used liquid, semi-solid, and solid dosage forms for vaginal drug delivery have several limitations, including short residence time, discomfort, leakage, imprecise dosing, and variable drug distribution [17]. On the other hand, nanofibers have a high surface-to-volume ratio and can provide high drug loading, controlled release, cell binding, good bioavailability, and cost-effectiveness [18].

Nanofibers are produced by electrospinning, which is based on the drying of a thin liquid jet that is formed from a drop of polymer solution in a strong electric field [19] and are used in numerous applications [20,21]. They also represent an effective material for delivering different types of drugs to the nasal, oral, and vaginal mucosa [22], while at the same time, they protect drugs from environmental factors [23]. Different compounds can be incorporated into nanofibers, including small drug molecules, proteins, nucleic acids, and cells. Lactobacillus bacteria have also been incorporated into electrospun nanofibers, with L. plantarum being the most frequently used [24-28]. Other Lactobacillus species have also been electrospun using different polymers, namely, agrowaste amended with poly (vinyl alcohol) for Lactobacillus acidophilus [29], poly (vinyl alcohol) and sodium alginate for Lactobacillus rhamnosus [30], poly (vinyl alcohol) for Lactobacillus gasseri [31], and Eudragit L100 and sodium alginate for Lactobacillus paracasei [32]. In a recent study, we successfully incorporated nine different Lactobacillus species into polyethylene oxide (PEO) nanofibers (i.e., L. acidophilus, L. delbrueckii ssp. bulgaricus, L. casei, L. gasseri, L. paracasei, L. plantarum, L. reuteri, L. rhamnosus, L. salivarius) with high viability after electrospinning process [33]. However, few studies have reported incorporation of vaginal lactobacilli. One example was the incorporation of L. gasseri CRL1320 and L. rhamnosus CRL1332 into polyvinyl-alcohol nanofibers, with skimmed milk lactose and glycerol serving as bioprotective agents [34]. In another study, vaginal L. acidophilus was incorporated into polyvinyl alcohol and polyvinylpyrrolidone nanofibers [35].

Apart from the lack of delivery systems, vaginal probiotics use is hampered by the lack of research into their distribution and mechanism of action [36]. The spatial identification of individual strains in mixtures is particularly challenging, as stains (such as Syto 9) cannot be used to distinguish them, and custom antibodies against specific surface antigens or fluorescent in-situ hybridization have to be used instead [37]. Genetic engineering of lactobacilli for the production of fluorescent proteins is a rapid and effective method for tracking and distinguishing lactobacilli. Fluorescent proteins with different spectral properties have already been used to study the distribution and properties of lactobacilli [38-42]. However, few studies have reported the incorporation of fluorescent lactobacilli into nanofibers. In our recent study, L. plantarum expressing red fluorescent protein mCherry was incorporated into PEO nanofibers to evaluate nanofiber dissolution and lactobacilli release [27].

The aim and novelty of the present study was to engineer vaginal lactobacilli to express fluorescent proteins and incorporate them into nanofibers. Four different species of lactobacilli (L. crispatus, L. gasseri, L. jensenii, and L. plantarum) were genetically modified to express compatible fluorescent proteins with different spectral properties: infrared fluorescent protein (IRFP); green fluorescent protein (GFP); red fluorescent protein (mCherry); and blue fluorescent protein (mTagBFP2). Quantification of their fluorescence, the overlap between the fluorescences of the different fluorescent proteins, and the differentiation between the fluorescent species were evaluated. The four engineered species were mixed with PEO solution and electrospun into nanofibers as the potential delivery system. By using genetic engineering, we have introduced a new technique for effective, inexpensive, and real-time tracking of probiotics following their incorporation into nanofibers and nanofiber dissolution. 


\section{Results}

\subsection{Genetic Constructs for Expression of Fluorescent Proteins in Vaginal Lactobacilli}

To complement the existing pNZ-ldh-GFP plasmid that encodes GFP under the control of the $l d h$ promoter from $L$. plantarum, genes that encode the fluorescent proteins IRFP, mCherry, and mTagBFP2 were scarlessly fused with the ldh promoter using overlapextension PCR (Figure 1). The gene fusions were cloned into the pNZ1848 plasmid, thereby replacing the inducible nisin promoter and yielding plasmids pNZ-ldh-IRFP, pNZ-ldhmCherry, and pNZ-ldh-mTagBFP2. All four plasmids were separately transformed in all four Lactobacillus species, yielding 16 combinations (Table S1) and thus providing a wide range of possibilities to distinguish between them when used simultaneously. They were characterized in the following experiment with respect to the intensity of the expressed fluorescent proteins.

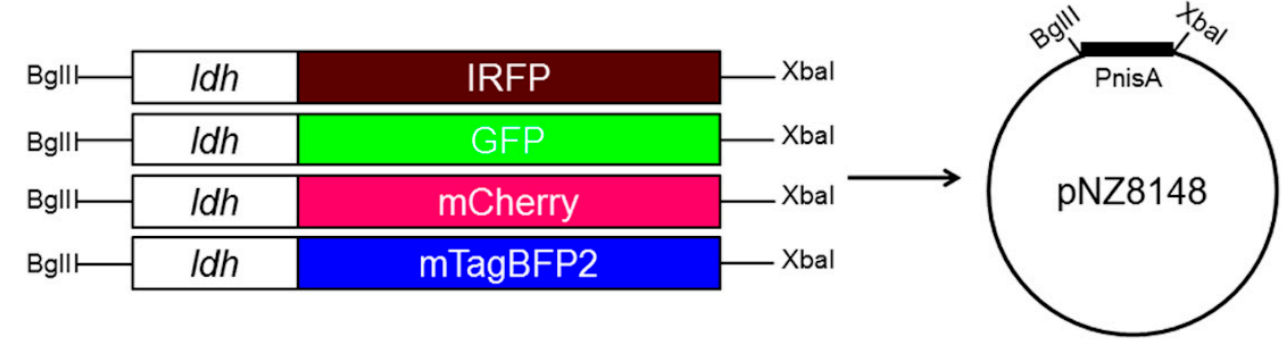

Figure 1. Assemblies of the $l d h$ promoter and the four genes that encode the fluorescent proteins (IRFP, GFP, mCherry, mTagBFP2) in pNZ8148 plasmid. BgIII, XbaI-restriction recognition sites that were used for cloning; PnisA-nisin promoter.

\subsection{Analysis of Fluorescent Protein Expression in Vaginal Lactobacilli}

Fluorescent protein expression in lactobacilli was confirmed by measuring the fluorescence of all 16 bacterial suspensions and was shown to be appropriate for the detection of bacteria (Figure 2). The expression of the individual fluorescent proteins depended on the culture conditions and differed between the species. Growing the bacteria with shaking (aeration) resulted in higher fluorescence per unit $\mathrm{OD}_{600}$ in comparison to the samples grown without shaking (Figure 2) and significantly steeper slopes of regression lines (Table S1). This is in accordance with previous observations of oxygen-mediated posttranslational activation of fluorescent proteins [43]. Fluorescent proteins GFP and TagBFP2 were expressed in all four strains at aerobic conditions, with 42,000 \pm 2000 fluorescence units (FU) in suspensions at $\mathrm{OD}_{600}$ 3.0. By contrast, the expression of IRFP and mCherry was strain-dependent and was highest in L. plantarum (1100 FU for IRFP and 42,500 FU for $\mathrm{mCherry).} \mathrm{In} \mathrm{comparison,} \mathrm{the} \mathrm{fluorescence} \mathrm{of} \mathrm{mCherry} \mathrm{in} \mathrm{other} \mathrm{lactobacilli} \mathrm{was} \mathrm{lower} \mathrm{by} \mathrm{a}$ factor of 2.4 for L. gasseri, a factor of 20.5 for L. jensenii, and a factor of 424 for L. crispatus. The fluorescence of these bacteria expressing the fluorescent proteins correlated linearly with a bacterial concentration in the $\mathrm{OD}_{600}$ range between 0.25 and 3.00 (Figure 2). The coefficients of determination $\left(R^{2}\right)$ for the engineered bacteria were above 0.96 with the exception of L. plantarum expressing mTagBFP2 and L. crispatus expressing IRFP, where $\mathrm{R}^{2}$ was lower (Supplementary Material: Table S1).

The nontransformed lactobacilli were used as controls because of the possibility of their autofluorescence. No or little concentration-dependent autofluorescence was seen for IRFP, GFP, and mCherry. Although bacteria showed relatively strong and concentrationdependent autofluorescence when measured using settings corresponding to mTagBFP2, the absolute fluorescence of nontransformed bacteria was significantly lower in comparison to the transformed bacteria.

The expression of the fluorescent proteins in these vaginal lactobacilli was also detected under a confocal microscope (Figure 3). Fluorescence was detected for all the engineered lactobacilli, while no fluorescence was detected for the nontransformed lactobacilli when using the settings for IRFP and mCherry. Some autofluorescence was seen for 
the nontransformed bacteria when using the settings for GFP and mTagBFP2; however, the signals were lower in comparison to those of the engineered bacteria.
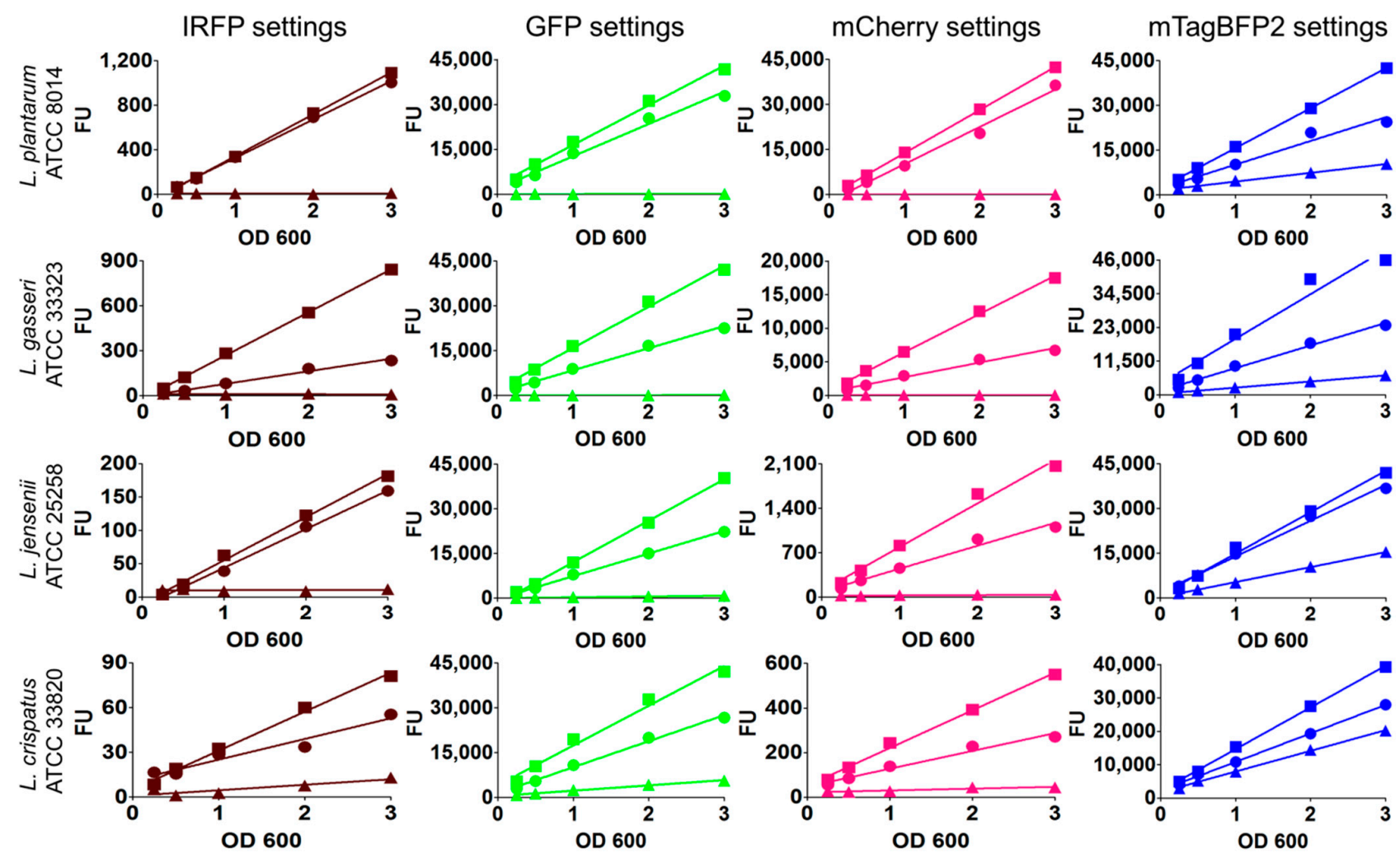

Without shaking

Shaking

Shaking - NT bacteria

Figure 2. Concentration-dependent fluorescence of lactobacilli expressing different fluorescent proteins. Linear regression analyses of fluorescence and $\mathrm{OD}_{600}$ of lactobacilli grown at $37^{\circ} \mathrm{C}$ without and with shaking (aeration) are shown. Nontransformed (NT) bacteria were used as controls. FU-fluorescence unit.

\subsection{Fluorescence-Based Distinction between Lactobacilli in Mixture and Assessment of the Influence of Spectral Overlap}

The individual Lactobacillus species were transformed with all four of the plasmids that encoded these fluorescent proteins with different spectral properties. Engineered strains of the same species of lactobacilli were mixed in different proportions, and their fluorescence was measured in a suspension (Figure 4). For the majority of the mixtures, the individual fluorescent strain was clearly distinguished by significantly higher fluorescence when using the settings corresponding to the fluorescent protein it expressed (i.e., the relevant excitation and emission wavelengths). Additionally, the fluorescence signals correlated with the content of the individual strain in the mixtures. The lowest specificity was observed with the mTagBFP2 settings, especially in the case of L. plantarum, where considerable fluorescence was also seen for other fluorescent proteins. This was attributed to shorter wavelengths and bacterial autofluorescence.

\subsection{Selection and Analysis of Optimal Lactobacilli-Fluorescent Protein Combinations}

To enable the distinction between the Lactobacillus species in complex mixtures or probiotic products, and thereby facilitate characterization in further studies, each species was defined with an individual fluorescent protein on the basis of the fluorescence properties of all 16 lactobacilli and fluorescent protein combinations, as follows: L. plantarum, IRFP; L. crispatus, GFP; L. gasseri, mCherry; and L. jensenii, mTagBFP2 (Figure 4). The fluorescence of the individual strains and their mixtures in the different proportions was measured, and the nontransformed lactobacilli were used as controls (Figure 5). Again, the individual 
fluorescent species were clearly distinguished by significantly higher fluorescence when using the settings corresponding to the fluorescent protein they expressed (i.e., the relevant excitation and emission wavelengths), and the fluorescence signals correlated with the contents of the individual strain in the mixtures (Figure 5). When using the settings for IRFP and mCherry (i.e., for determination of L. plantarum and L. gasseri, respectively), no fluorescence was observed for the nontransformed bacteria (i.e., no autofluorescence) or for the other fluorescent lactobacilli. However, stronger autofluorescence of the nontransformed lactobacilli was seen for the measures with the GFP settings (i.e., for L. crispatus), with the strongest seen for the measures with the mTagBFP2 settings (i.e., for L. jensenii). The autofluorescence was also species specific, whereby L. plantarum showed the lowest autofluorescence using the GFP and mTagBFP2 settings. Considerable overlap was observed between L. crispatus that expressed GFP and L. jensenii that expressed mTagBFP2, where individual bacteria were detected in both of the fluorescence channels.

However, with confocal microscopy, the majority of the lactobacilli that expressed the different fluorescent proteins were distinguished on the basis of their fluorescence when in mixtures of equal ratios (Figure 6).

\subsection{Incorporation of Fluorescent Lactobacilli into PEO Electrospun Nanofibers}

Fluorescent species of vaginal lactobacilli were successfully incorporated into PEO nanofibers as a potential vaginal delivery system, both individually and as mixtures, including the smallest species (L. plantarum: length, $1.28 \pm 0.32 \mu \mathrm{m}$; width, $0.52 \pm 0.04 \mu \mathrm{m}$ ) and the largest species (L. crispatus: length, $7.73 \pm 1.89 \mu \mathrm{m}$; width, $0.81 \pm 1.31 \mu \mathrm{m}$ ). The mean diameter of the PEO nanofibers without the bacteria was $170 \pm 40 \mathrm{~nm}$, and the bacteria incorporation was seen as characteristic thickenings along the nanofibers as reported previously $[27,33]$. The incorporation of L. plantarum, L. gasseri, and L. crispatus resulted in the increase of the mean nanofiber diameter by app. $100 \mathrm{~nm}$, while the incorporation of $L$. jensenii caused no increase (Figure 7). This may be due to the bacterial release of molecules, such as exopolysaccharides or ions, that can influence the conductivity or viscosity of the polymer suspension.

Effective incorporation of these bacteria into the nanofibers was also confirmed using confocal microscopy (Figure 8). All of the recombinant species retained their fluorescence following their incorporation in the nanofibers, while no fluorescence was observed for the nontransformed lactobacilli, which were incorporated as the controls. The different lactobacilli could be distinguished in the mixtures on the basis of their fluorescence, although some overlap was observed for L. crispatus expressing GFP and L. jensenii expressing mTagBFP2. This was similar to the data obtained for the bacterial suspensions (Figure 6).

\subsection{Release of Lactobacilli from Nanofibers}

The lactobacilli from the nanofibers retained their fluorescence after the dissolution of nanofibers. The lower intensity of the fluorescence observed with the dissolved nanofibers was in line with the lower concentration of the lactobacilli in the dissolved nanofibers in comparison to the original dispersions. Namely, the concentration of bacteria per PEO mass was estimated to be on average 3.6-fold higher in suspension than in nanofibers, preventing direct comparison of absolute fluorescence values. Nevertheless, similar to the data above, the fluorescence intensities correlated with the bacterial concentrations in the dissolved nanofibers, as well as in the control $4 \%(w / v)$ PEO bacterial dispersions (Figure 9a). Here, a $4 \%(w / v)$ PEO solution and the dissolved PEO nanofibers without bacteria were used as the negative controls with significantly lower fluorescence. With the exception of $L$. jensenii, the bacteria-containing polymer dispersion and dispersion from nanofibers showed no autofluorescence, regardless of their concentration. 


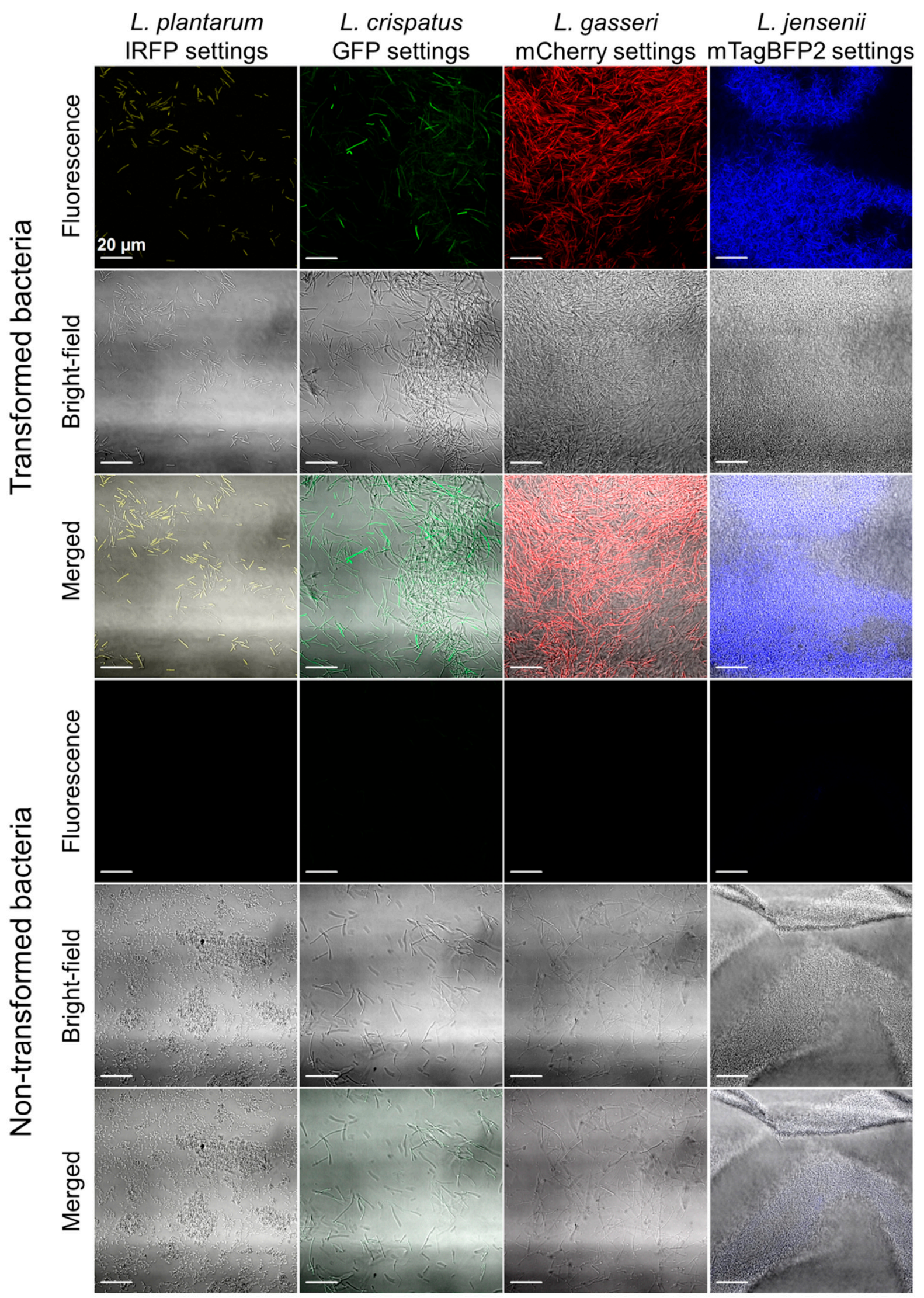

Figure 3. Representative confocal microscopy images of the lactobacilli expressing the different fluorescent proteins, as $L$. plantarum expressing IRFP, L. gasseri expressing mCherry, L. crispatus expressing GFP, and L. jensenii expressing mTagBFP2, in comparison to the nontransformed bacteria. 

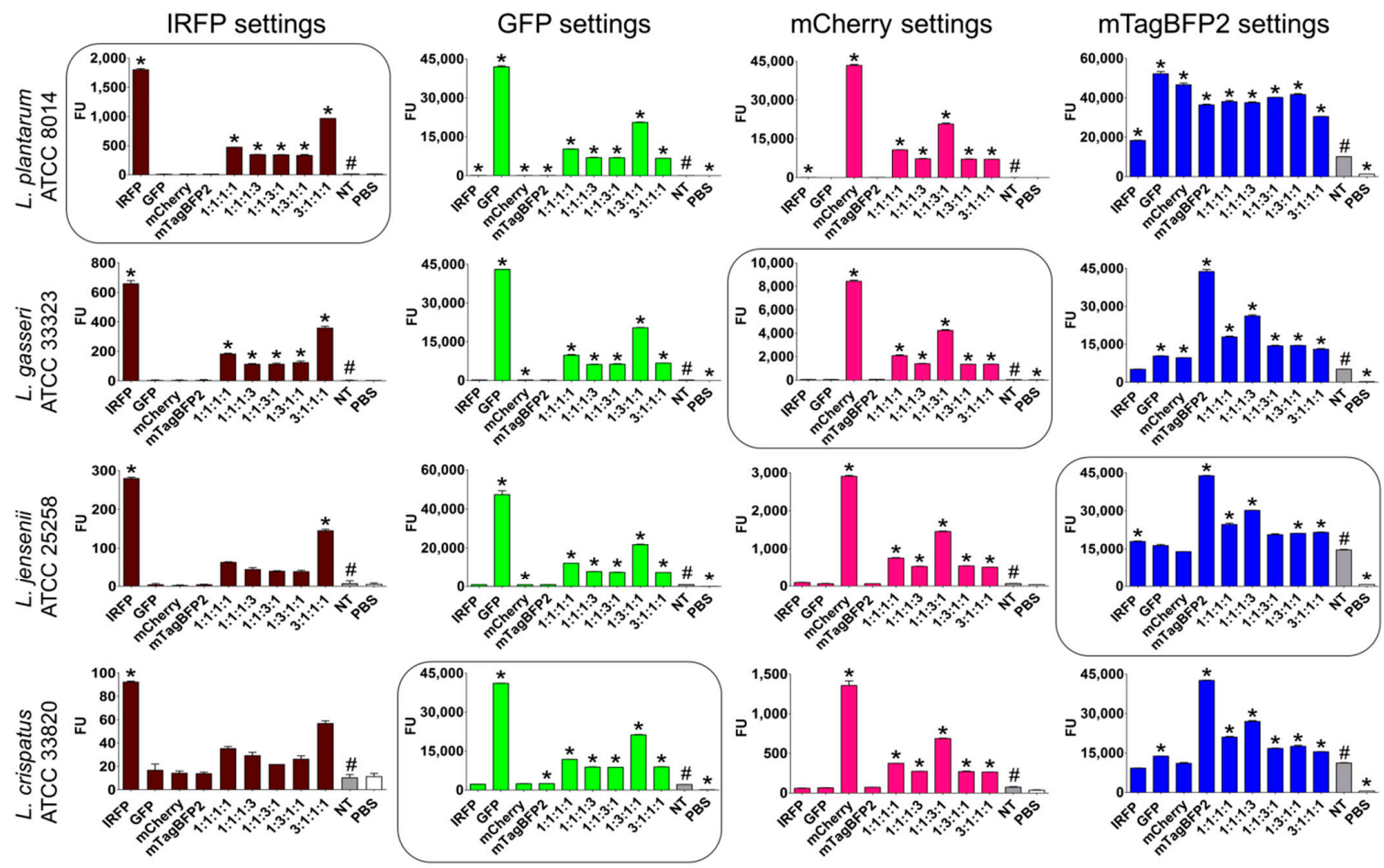

Figure 4. Distinction between the same species of Lactobacillus expressing different fluorescent proteins. Fluorescence was measured for the individual fluorescent strains and their mixtures, using settings corresponding to all four of the fluorescent proteins. The ratios indicate the proportions of the species expressing the fluorescent proteins in the following order: IRFP:GFP:mCherry:mTagBFP2. The encircled graphs represent the combination of fluorescent proteins and lactobacilli that were selected for further studies. ${ }^{*} p<0.05$ (Student's $t$ tests) relative to nontransformed strain (NT, high-lighted with \# for clarity). FU—fluorescence units; PBS—-phosphate-buffered saline.
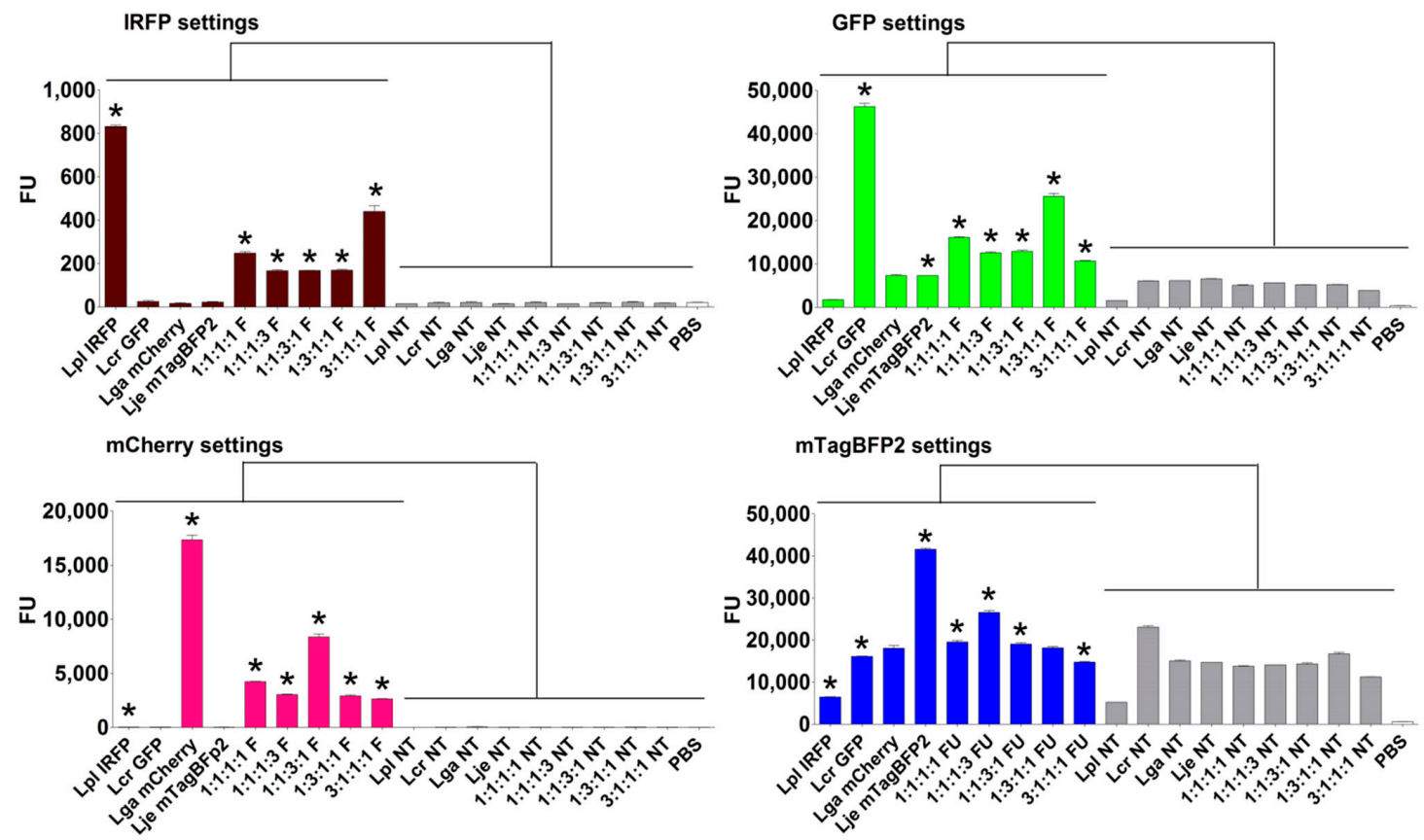

Figure 5. Fluorescence-based distinction of the different fluorescent lactobacilli and the nontransformed (NT) lactobacilli. Fluorescence was measured for the individual fluorescent species or their mixtures using the settings for all four of the fluorescent proteins. The ratios indicate the proportions of species in the mixtures in the following order: L. plantarum expressing IRFP; L. crispatus expressing GFP; L. gasseri expressing mCherry; and L. jensenii expressing mTagBFP2. * $p<0.05$ (Student's $t$ tests), obtained by comparing fluorescent strain (F) to its nontransformed counterpart (NT). Lpl—L. plantarum; Lga-L. gasseri; Lcr-L. crispatus; Lje-L. jensenii; PBS—phosphate-buffered saline. 


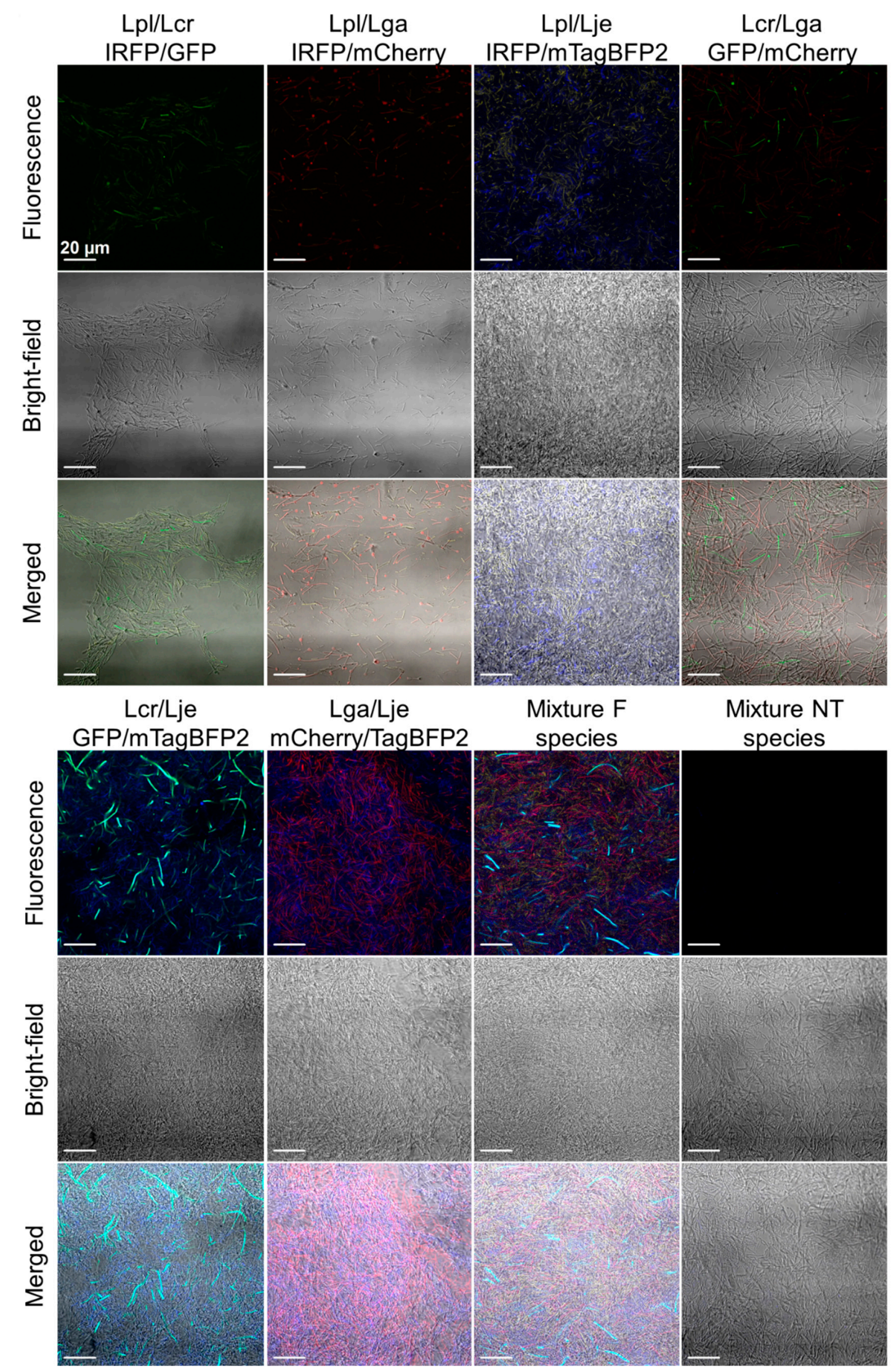

Figure 6. Representative confocal microscopy images of the mixtures of the lactobacilli expressing the different fluorescent proteins (F). Lpl—L. plantarum; Lga—L. gasseri; Lcr—L. crispatus; Lje-L. jensenii; NT—nontransformed species. Fluorescence images were obtained by using settings for denoted fluorescent proteins and merging thus obtained images, whereby settings for all four fluorescent proteins were used for the mixture. 

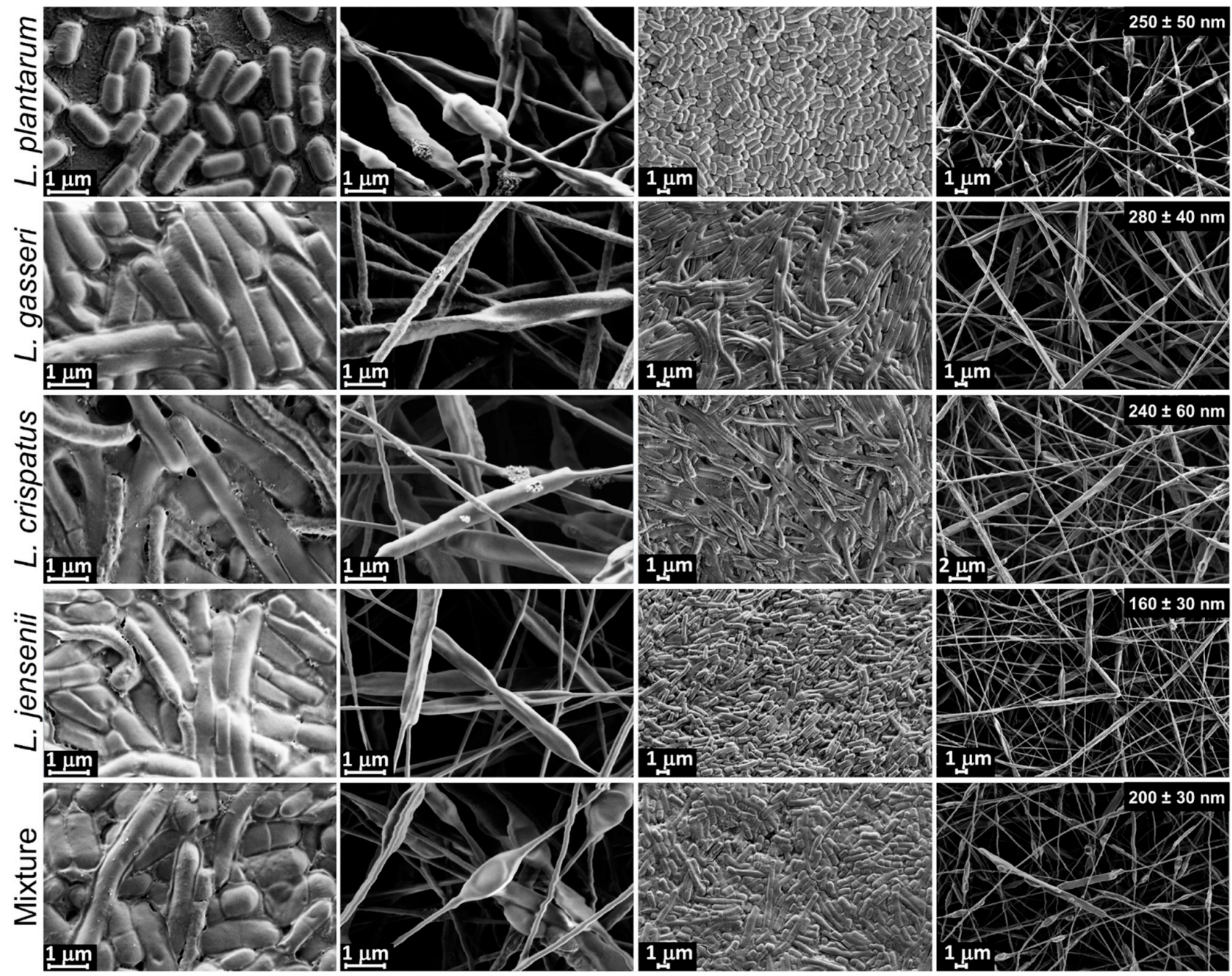

Figure 7. Scanning electron microscopy images of individual lactobacilli and as mixtures under high and low magnification. Columns 1 and 3, air-dried bacteria from water suspensions; Columns 2 and 4, bacteria incorporated into nanofibers. Average nanofiber diameters are specified in the last column.

As well as the individual species (Figure 9a), mixtures of all four of these fluorescent lactobacilli were incorporated into PEO nanofibers, with the fluorescence evaluated following the dissolution (Figure 9b). The IRFP-expressing and mCherry-expressing bacteria produced no fluorescence when the settings for the other fluorescent proteins were used. This was not the case for the GFP-expressing and mTagBFP2-expressing bacteria, for which significant fluorescence was observed also when using the settings for the other fluorescent proteins. Additionally, fluorescence overlap was seen, in terms of the fluorescence detected for mCherry-expressing and GFP-expressing bacteria when using the GFP and mTagBFP2 settings, respectively. 


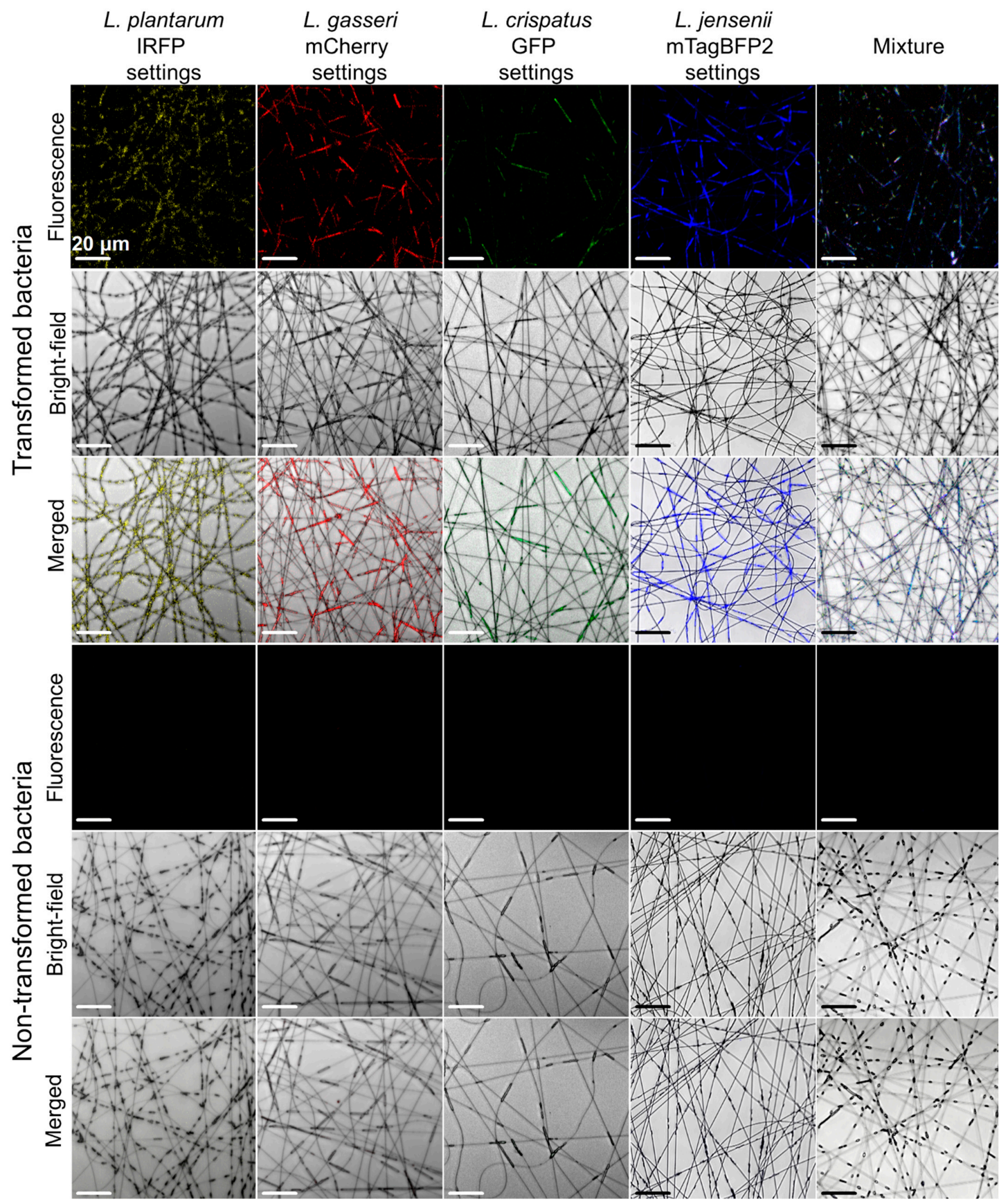

Figure 8. Representative confocal microscopy images of the fluorescent lactobacilli and the nontransformed lactobacilli when incorporated in PEO electrospun nanofibers individually or as mixture of all 4 fluorescent lactobacilli. 
a
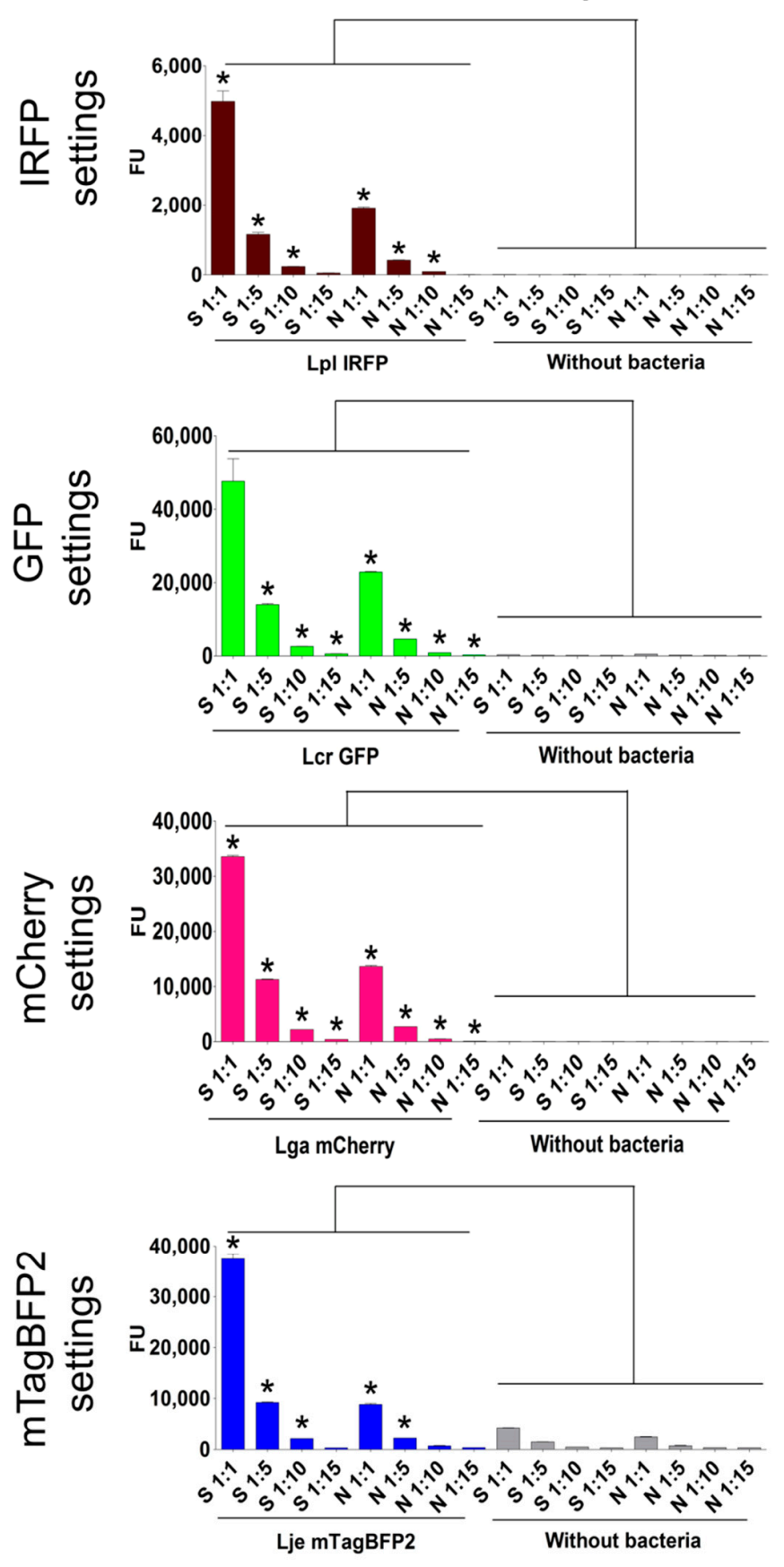
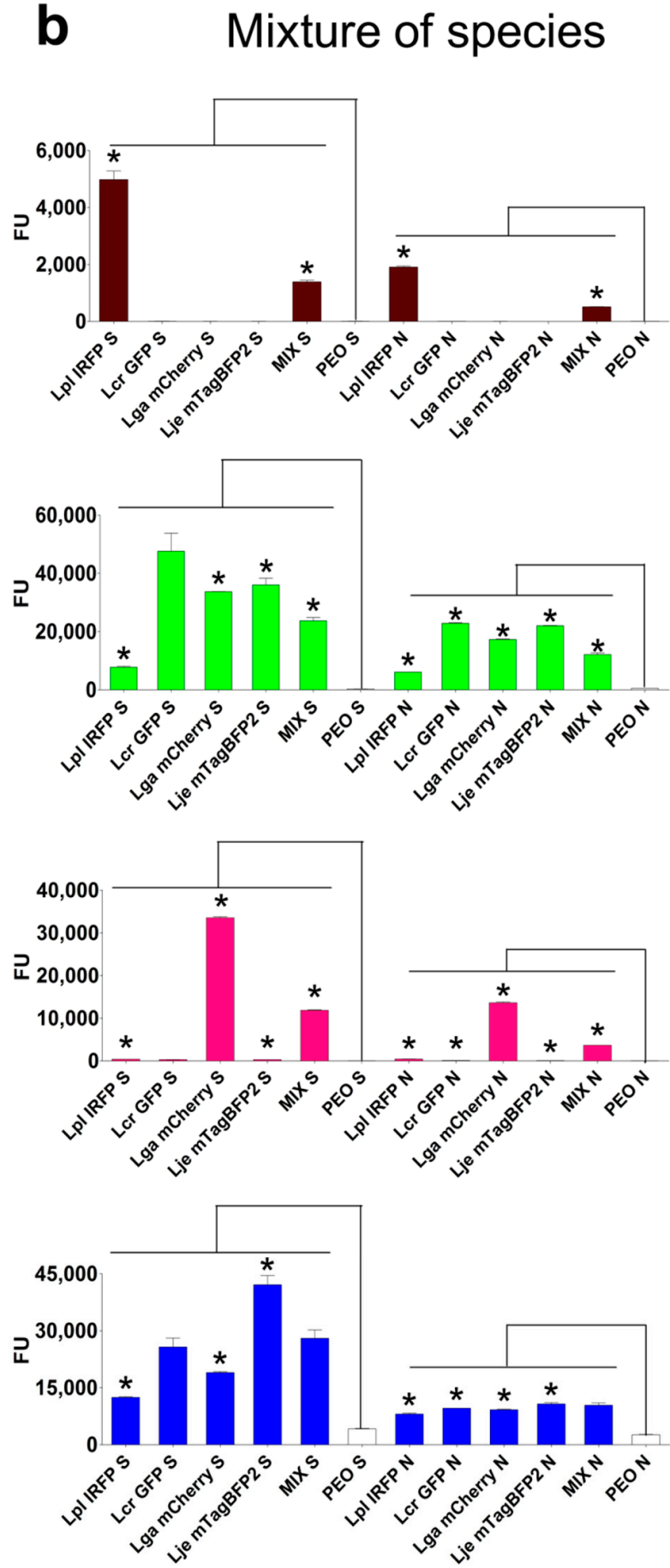

Figure 9. Fluorescence intensities of individual fluorescent Lactobacillus species (a) and for their mixtures containing all four of the Lactobacillus species (b), both as dispersed in $4 \%(w / v)$ PEO (S, suspension) prior to incorporation and after their release from the nanofibers $(\mathrm{N})$. Ratios indicate different dilution factors (ratios of the aliquot volume to the final volume). * $p<0.05$ (Student's $t$ tests), comparison of suspensions or nanofibers containing fluorescent strain to its counterpart without bacteria (a), or comparison of suspensions and nanofibers containing fluorescent strains or their mixtures to corresponding PEO control (b). PEO—polyethylene oxide.

\section{Discussion}

To establish methods for imaging of the vaginal lactobacilli, three vaginal Lactobacillus species, L. gasseri ATCC 33323, L. crispatus ATCC 33820, and L. jensenii ATCC 25258, and the control L. plantarum ATCC 8014 were genetically modified to express fluorescent proteins with different spectral properties: IRFP, GFP, mCherry, and mTagBFP2. This genetic 
engineering of the vaginal lactobacilli was challenging, particularly for L. crispatus [44]. Here, it was performed by electrotransformation using modified and optimized previously published protocols [45-47].

Expression of the fluorescent proteins varied between the bacterial species and was highest in the control L. plantarum, regardless of the fluorescent protein used. This might be associated with the use of the $l d h$ promoter for the control of the transcription of the fluorescent proteins, which originated from L. plantarum. The fluorescent intensities of the species were influenced by the growth conditions. According to expectation, higher fluorescence was observed when the lactobacilli were grown with aeration, as the presence of oxygen is crucial for post-translational maturation of the fluorescent proteins, resulting in exo-methylene double bond formation that prevents isomerization [43]. However, these conditions were not favorable for these lactobacilli, which are anaerobes or facultative anaerobes $[48,49]$. To further improve this approach, anaerobic fluorescent proteins could be considered. Expression of mTagBFP2 affected the growth of L. plantarum (not shown), which suggested possible phototoxicity. Nevertheless, all of these species expressed all of these fluorescent proteins, and the fluorescence measurements were proportional to the bacterial concentrations, thus also defining the suitability of this approach for quantifying these bacteria. Very little autofluorescence was seen for the nontransformed bacteria, except when using the mTagBFP2 settings. This contrasted with the expression of mTagBFP2 in L. rhamnosus, where autofluorescence was not an issue [42].

The expression of these different fluorescent proteins was also used to distinguish between these different bacterial species in mixtures containing species in equal ratios or in mixtures in which one of the species predominated. This resulted in a very useful tool to gain better insight into the behavior of the lactobacilli in future studies. The fluorescence signals correlated with the contents of the individual strains in the mixtures; however, the overlap between the different fluorescent proteins expressed by the same or different species was also observed. This was particularly evident for mTagBFP2; when using the mTagBFP2 settings, there was considerable fluorescence determined also for the other fluorescent proteins. Further, considerable overlap was observed between L. crispatus expressing GFP and L. jensenii expressing mTagBFP2, where the individual bacteria were detected in both fluorescence channels. We concluded that fluorescent proteins can be applied to distinguish between vaginal lactobacilli; however, proteins with longer excitation and emission wavelengths (IRFP, mCherry) are more appropriate due to the lower autofluorescence.

Most of the probiotic dosage forms are designed for oral application due to their beneficial effects on the gut. For therapeutic effects in the vagina, intravaginal administration of the probiotics is crucial [50]. To allow intravaginal applications of Lactobacillus probiotics, we incorporated these into small diameter fibers, i.e., nanofibers, which were produced using electrospinning [19]. Electrospun nanofibers represent a next-generation delivery system that can be used for biologicals, such as microorganisms, stem cells, proteins, and nucleic acids [23]. The incorporation of bacteria affects the characteristics of nanofibers [33]. Here, a change in diameter was observed, which may be due to the release of bacterial products that can influence the properties of the polymer suspension. Lactobacilli retained their fluorescence after incorporation into nanofibers, as well as after dissolution of the nanofibers, and the fluorescence intensities again correlated with the bacterial concentrations. In bacterial mixtures, the fluorescent proteins with longer excitation and emission wavelengths (i.e., mCherry, IRFP) were clearly distinguished, while for mTagBFP2 and GFP, autofluorescence and spectral overlap interfered with these measurements; this might be resolved with the appropriate compensation. The proposed approach represents a clear advantage over non-specific bacterial staining in pre-formulation and formulation studies of lactobacilli-containing nanofibers. 


\section{Materials and Methods}

\subsection{Bacterial Strains and Culturing}

Four different strains from the genus Lactobacillus were used in this study: L. crispatus ATCC 33820; L. gasseri ATCC 33323; L. jensenii ATCC 25258; and L. plantarum ATCC 8014). Lactococcus lactis NZ9000 and E. coli DH5 $\alpha$ were used as the cloning hosts. Lactobacilli were grown in De Man, Rogosa, and Sharpe (MRS) medium (Merck, Darmstadt, Germany) at $37^{\circ} \mathrm{C}$ without and with aeration. Lc. lactis NZ9000 was grown in M-17 medium (Merck) supplemented with $0.5 \%(v / v)$ glucose $(\mathrm{GM}-17)$ at $30{ }^{\circ} \mathrm{C}$, without aeration. E. coli was grown in a lysogeny broth medium at $37^{\circ} \mathrm{C}$, with aeration. All of the strains were kept frozen at $-80^{\circ} \mathrm{C}$ for long-term storage.

\subsection{Plasmid Construction}

KOD Hot Start DNA polymerase (Merck Millipore, Burlington, MA, USA) was used to fuse the fluorescent protein genes with the $l d h$ promoter using overlap-extension PCR [51].

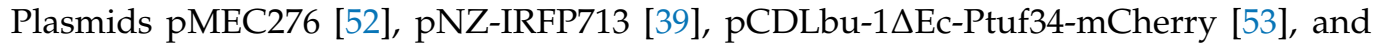
pBAD-mTagBFP2 [54] were used as templates for ldh, IRFP, mCherry, and $m T a g B F P 2$, respectively. Three individual PCR reactions were prepared using the primers (Integrated DNA Technologies, Leuven, Belgium) specified in Supplementary Material: Table S2. In the first reaction, the promoter and fluorescent protein genes were amplified, and DNA overlaps were introduced (e.g., for ldh-IRFP fusion, primer pairs ldh-F/ldh-IRFP-R and IRFP-ldh-F/IRFP-R were used). These two DNA fragments were put in a new PCR mixture without primers to allow direct fusion of the two DNA fragments via complementary overlaps. Finally, in the third PCR reaction, the fused promoter and gene were amplified with a forward primer of the promoter and reverse primer of the fluorescent protein gene (e.g., ldh-F/IRFP-R for ldh-IRFP). Gene fusions ldh-mCherry and $l d h-m T a g B F P 2$ were prepared in a similar fashion. The DNA products were then inserted into the pJET1.2/blunt vector and transformed into DH5 $\alpha$ competent $E$. coli cells. Cloned products were digested using the $\mathrm{XbaI} / \mathrm{BglII}$ restriction enzymes (Thermo Scientific, Waltham, MA, USA) and ligated into the pNZ8148 [55] plasmid using T4 DNA ligase (Thermo Scientific, Waltham, MA, USA). The three pNZ8148 derivatives thus obtained were: pNZ-ldh-IRFP, pNZ-ldh-mCherry, and pNZ-ldh-mTagBFP2. For the expression of GFP, the plasmid pMEC276 that contained ldh-GFP (for clarity, also indicated as pNZ-ldh-GFP) was kindly provided by C. Daniel [52]. The plasmids were transformed into Lc. lactis NZ9000 with electroporation using a Gene Pulser II apparatus (Biorad, Hercules, CA, USA), according to the manufacturer instructions (MoBiTec $\mathrm{GmbH}$, Goettingen, Germany). Plasmids were isolated using peqGOLD Plasmid Miniprep Kit I (Peqlabs, Erlangen, Germany) and NucleoSpin Plasmid (Macherey and Nagel, Düren, Germany). Additional treatments with mixtures of lysozyme $(50 \mathrm{mg} / \mathrm{mL})$ and mutanolysin were performed when isolating from Lc. lactis. Genetic constructs were confirmed by nucleotide sequencing (Eurofins Genomics, Ebersberg, Germany).

\subsection{Electrotransformation of Lactobacilli}

The electrotransformation of lactobacilli was performed with a Gene Pulser II apparatus. Bacterial suspensions $(100 \mu \mathrm{L})$ were mixed with $5 \mu \mathrm{L}$ or $10 \mu \mathrm{L}$ plasmid DNA (200-300 ng/ $\mu \mathrm{L}$ ) and added to an electroporation cuvette. The species-specific conditions for electroporation and electrocompetent cell preparation are as specified below. After electroporation, $1 \mathrm{~mL}$ fresh MRS medium was added to the bacteria, which were then left for 2-3 $\mathrm{h}$ to recover, at $30^{\circ} \mathrm{C}$ or $37^{\circ} \mathrm{C}$. After the recovery, the bacteria were plated on MRS plates containing $10 \mu \mathrm{g} / \mathrm{mL}$ chloramphenicol (MRSC10). The plates were then placed into anaerobic bags (GasPak ${ }^{\mathrm{TM}}$ EZ; Becton Dickinson, Franklin Lakes, NJ, USA) or jars (AnaeroGen $^{\mathrm{TM}}$ 2.5l; Thermo Scientific, Waltham, MA, USA) and incubated at $37^{\circ} \mathrm{C}$ for $48 \mathrm{~h}$ to $72 \mathrm{~h}$.

Electroporation-competent $L$. plantarum was prepared as previously described [45]. Fresh overnight cultures of L. plantarum were inoculated in $50 \mathrm{~mL}$ MRS medium at 1:50 and grown at $30{ }^{\circ} \mathrm{C}$ until an optical density at $600 \mathrm{~nm}\left(\mathrm{OD}_{600}\right)$ of $0.4-0.6$. The bacteria were 
then washed twice with $10 \mathrm{~mL} 10 \mathrm{mM} \mathrm{MgCl}$ and once with $10 \mathrm{~mL}$ electroporation buffer $(0.5 \mathrm{M}$ sucrose, $10 \%(v / v)$ glycerol). The electroporation parameters for the transformation of L. plantarum were: $25 \mu \mathrm{F}, 600 \Omega$, and $1.8 \mathrm{kV}$. After electroporation, the bacteria were left to recover at $30^{\circ} \mathrm{C}$ for $2 \mathrm{~h}$. A similar protocol was used for L. jensenii, with a higher growth and recovery temperature $\left(37^{\circ} \mathrm{C}\right)$ and a higher voltage applied during electroporation $(2.4 \mathrm{kV})$.

To prepare electrocompetent $L$. gasseri, overnight cultures were inoculated in $50 \mathrm{~mL}$ MRS medium at 1:50 and grown at $37^{\circ} \mathrm{C}$ until an $\mathrm{OD}_{600}$ of 0.4 . Then, ampicillin $(10 \mu \mathrm{g} / \mathrm{mL})$ was added, and the bacteria were incubated to an $\mathrm{OD}_{600}$ of 0.8 , followed by three washes with $0.5 \mathrm{M}$ sucrose. L. gasseri was electroporated at $25 \mu \mathrm{F}, 400 \Omega$, and $2.4 \mathrm{kV}$, and allowed to recover at $37^{\circ} \mathrm{C}$ for $3 \mathrm{~h}$, before plating on MRSC10 plates [47].

Overnight cultures of L. crispatus were inoculated into $10 \mathrm{~mL}$ sterile-filtered MRS medium containing $0.8 \%(w / v)$ glycine, and left for $\sim 10 \mathrm{~h}$ at $37^{\circ} \mathrm{C}$ until reaching an $\mathrm{OD}_{600}$ of 0.5 . The bacteria were washed twice with $0.5 \mathrm{M}$ sucrose, incubated on ice with $50 \mathrm{mM}$ EDTA for $5 \mathrm{~min}$, and again washed with $0.5 \mathrm{M}$ sucrose. Electroporation was performed at $25 \mu \mathrm{F}, 600 \Omega$, and $1.5 \mathrm{kV}$ [46]. Before plating on MRSC10 plates, the bacteria were left to recover at $37^{\circ} \mathrm{C}$ for $3 \mathrm{~h}$.

The transformed bacteria were kept frozen at $-80{ }^{\circ} \mathrm{C}$ in MRS with $20 \%(v / v)$ glycerol for long-term storage.

\subsection{Culturing of Lactobacilli}

Different growth conditions were used for the lactobacilli for the different experiments. Lactobacilli were transferred from frozen stocks to solid MRS media and grown anaerobically at $37^{\circ} \mathrm{C}$ for $2-3$ days. A single colony was picked and grown in liquid MRS media for 1 day. For measurement of fluorescence, overnight cultures of Lactobacillus species transformed with the fluorescent proteins encoded in the $\mathrm{pNZ}$ plasmids were inoculated in $5 \mathrm{~mL}$ MRSC10 medium and grown at $37^{\circ} \mathrm{C}$ without and with aeration, and without and with shaking (180-200 rpm). Biliverdin ( $15.5 \mu \mathrm{g} / \mathrm{mL}$; Sigma Aldrich, St. Louis, MO, USA) was added to the medium of species engineered to produce IRFP. The species were grown until late exponential or early stationary phase $\left(\mathrm{OD}_{600} 1.5-2.0\right)$ when the bacteria were centrifuged at $4400 \times g$ for $10 \mathrm{~min}$ at $4{ }^{\circ} \mathrm{C}$ (Centrifuge $5702 \mathrm{R}$; Eppendorf, St. Louis, MO, USA) and resuspended in phosphate-buffered saline (PBS, pH 7.4) to an $\mathrm{OD}_{600}$ of 3.0.

Prior to electrospinning, the engineered bacteria were grown in $400 \mathrm{~mL}$ at $37{ }^{\circ} \mathrm{C}$ with shaking until reaching $\mathrm{OD}_{600}$ of 2.0-3.0. The bacteria were washed twice with water and resuspended in $10 \mathrm{~mL}$ water. PEO powder (Mw $900 \mathrm{kDa}$; Sigma Aldrich, Darmstadt, Germany) was added to the lactobacilli suspensions and stirred at $400 \mathrm{rpm}$ at room temperature until the polymer was completely dissolved to provide the polymer concentration of $4 \%(w / v)$.

\subsection{Electrospinning of Lactobacilli}

Bacterial cells $\left(\mathrm{OD}_{600}\right.$ of 9.0-11.0) were mixed with PEO as described above. The homogenous bacterial-polymer suspensions were filled into a $5 \mathrm{~mL}$ syringe that was fixed to an electrospinning machine (Fluidnatek LE100; BioInicia SL, Valencia, Spain). A high voltage of $13 \pm 2 \mathrm{kV}$ was applied. The flow rate of the suspension in the syringe was $250-350 \mu \mathrm{L} / \mathrm{h}$, and the distance between the needle and collector was $15 \mathrm{~cm}$. The electrospinning process was conducted in a climate-controlled environment at $37^{\circ} \mathrm{C}$ and $17 \%$ relative humidity.

\subsection{Fluorescence Measurement}

The fluorescence of the bacterial suspensions in PBS $(200 \mu \mathrm{L})$ was measured using a microplate reader (Infinite M1000; Tecan, Männedorf, Switzerland) in 96-well black, flat-bottomed plates. All of the samples were measured in duplicate. Depending on the characteristics of the fluorescent protein, different excitation and emission wavelengths were applied: 402/457 nm for mTagBFP2; 488/509 nm for GFP; 587/610 nm for mCherry; 
and 690/713 nm for IRFP. The excitation and emission spectra of these fluorescent proteins are provided in Supplementary Material: Figure S1.

To test for correlations between the bacterial concentrations and the fluorescence intensities, serial dilutions of the bacteria were used, corresponding to $\mathrm{OD}_{600}$ of 3.0, 2.0, 1.0, 0.5 , and 0.25 . Nontransformed bacteria were included as the control.

The overlap of the fluorescence signals of the four different fluorescent proteins was assessed by mixing fluorescent strains either in equal ratios (1:1:1:1) or in ratios where individual strain represented $50 \%$ of all the bacteria (e.g., 3:1:1:1). These were then compared to the same ratios of the nontransformed bacteria. Individual species that expressed different fluorescent proteins were compared to assign each species with a unique fluorescent protein; selected combinations were L. plantarum expressing IRFP, L. gasseri expressing mCherry, L. crispatus expressing GFP, and L. jensenii expressing mTagBFP2, with these compared in a similar fashion. These were also used for confocal microscopy imaging and incorporation into nanofibers.

To measure the fluorescence of the lactobacilli following electrospinning, $10 \pm 3 \mathrm{mg}$ PEO nanofibers with the incorporated fluorescent lactobacilli were dissolved in $900 \mu \mathrm{L}$ PBS and diluted with PBS using the dilution factors (ratios of the aliquot volume to the final volume) of 1:1, 1:5, 1:10, and 1:15. The fluorescence intensities were compared to those of bacterial-polymer suspensions prior to electrospinning, where the concentration of bacteria was estimated to be $\sim 3.6$-fold higher. The same dilution factors were applied for the bacterial-polymer suspensions.

\subsection{Confocal Microscopy}

Lactobacilli were grown as described in section Culturing of lactobacilli, resuspended in PBS to an $\mathrm{OD}_{600}$ of 3.0, and fixed to a microscope slide with StatSpine Cytofuge 2 (Iris Sample Processing, Westwood, MA, USA) by centrifugation at maximum speed at $4400 \mathrm{rpm}$ for $10 \mathrm{~min}$. The samples were left at room temperature for $1 \mathrm{~h}$ to dry and then mounted with a mounting medium (Invitrogen, Waltham, MA, USA) with 4',6-diamidino-2-phenylindole (DAPI), or IBIDI mounting medium without DAPI. Fluorescent bacteria were visualized with a confocal microscope (LSM-710; Carl Zeiss, Oberkochen, Germany), and images were acquired and processed with the ZEN 2010 B SP1 software (Carl Zeiss, Oberkochen, Germany). The strains were detected with different settings: brightfield, DAPI, Alexa 488, Alexa 543, and Alexa 647, using the $63 \times$ immersion oil objective.

For imaging of the nanofibers, a microscope slide was added to the collector of the electrospinning machine, and it was left there for nanofibers to be deposited onto it. A cover slip was added on top and glued with nail polish. Imaging was performed as above, using the $40 \times$ immersion oil objective. Nontransformed bacteria were included as the control.

\subsection{Scanning Electron Microscopy}

A scanning electron microscope (Supra 35 VP; Carl Zeiss, Oberkochen, Jena, Germany) was used to visualize the nanofibers with the incorporated bacteria, as well as free bacteria. Individual species and their mixtures were dispersed in water, and $3 \mu \mathrm{L}$ of the suspension was pipetted onto a metal stub and air-dried. The double-sided conductive tape was used to attach the nanofiber mats to the metal stubs. The scanning electron microscopy was operated at an acceleration voltage of $1 \mathrm{kV}$, with a secondary electron detector. Bacterial and nanofiber size were analyzed using the ImageJ 1.51j8 software (National Institutes of Health, Bethesda, MD, USA), where the length and width of 30 randomly selected bacteria or nanofibers (regions without bacteria) were measured.

\subsection{Statistical Analyses}

Statistical analyses were performed using the GraphPad Prism 7.0 software, San Diego, CA, USA. Student's $t$ tests were used to define the significances of the differences between the fluorescent bacteria and their respective controls. Calculation of slopes of the regression 
lines and their comparison was also performed with GraphPad Prism 7.0. All of the data are presented as means \pm standard deviation (SD).

\section{Conclusions}

In this paper, we pursued two major goals for wider vaginal probiotics use, namely fluorescent labeling to allow for future distribution studies and designing of an appropriate delivery system. Three of the most important vaginal Lactobacillus species, L. gasseri, L. crispatus, and L. jensenii, and the control L. plantarum were engineered to produce compatible fluorescent proteins with different spectral properties. The fluorescence intensities were mostly dependent on lactobacilli species and growth conditions. The aeration during culturing promoted the expression of fluorescent proteins compared to samples grown without aeration. The four species were successfully incorporated into nanofibers by electrospinning, which indicated that this technique is appropriate for designing solid nanofiber-based vaginal delivery systems for probiotics. The lactobacilli retained their fluorescence after incorporation into these PEO nanofibers and after their release from them. This research presents a cutting-edge technology to accurately track, by fluorescence imaging, the release of lactobacilli from nanofibers and interactions with the indigenous vaginal microbiota in future in vitro and in vivo studies.

Supplementary Materials: The following are available online at https:/ /www.mdpi.com/article/10 $.3390 /$ ijms222413631/s1.

Author Contributions: S.S. carried out the experimental work and wrote the draft of the manuscript. T.V.P. assisted with confocal imaging. J.K. revised the manuscript and supervised the work. Š.Z. revised the manuscript, assisted with electrospinning, and performed scanning electron microscopy. A.B. revised the manuscript, planned, and supervised the work. All authors have read and agreed to the published version of the manuscript.

Funding: This work was funded by the Slovenian Research Agency (grants J4-9327, P1-0189 and P4-0127).

Institutional Review Board Statement: Not applicable.

Informed Consent Statement: Not applicable.

Data Availability Statement: The data presented in this study are available in the article or its Supplementary Material.

Acknowledgments: We thank Christopher Berrie for his critical reading of the manuscript. Our thanks also go to Catherine Daniel for providing pMEC276 and Vladislav Verkhusha for providing pBAD-mTagBFP2 (Addgene plasmid \#34632).

Conflicts of Interest: The authors declare no conflict of interest. The funders had no role in the design of the study; in the collection, analyses, or interpretation of data; in the writing of the manuscript, or in the decision to publish the results.

\section{References}

1. Cribby, S.; Taylor, M.; Reid, G. Vaginal microbiota and the use of probiotics. Interdiscip. Perspect. Infect. Dis. 2008, $2008,256490$. [CrossRef]

2. Petrova, M.I.; Lievens, E.; Malik, S.; Imholz, N.; Lebeer, S. Lactobacillus species as biomarkers and agents that can promote various aspects of vaginal health. Front. Physiol. 2015, 6, 81. [CrossRef]

3. Kim, J.M.; Park, Y.J. Probiotics in the prevention and treatment of postmenopausal vaginal infections: Review article. J. Menopausal Med. 2017, 23, 139-145. [CrossRef]

4. Simoes, J.A.; Aroutcheva, A.A.; Shott, S.; Faro, S. Effect of metronidazole on the growth of vaginal lactobacilli in vitro. Infect. Dis. Obstet. Gynecol. 2001, 9, 41-45. [CrossRef]

5. Kumar, N.; Behera, B.; Sagiri, S.S.; Pal, K.; Ray, S.S.; Roy, S. Bacterial vaginosis: Etiology and modalities of treatment-a brief note. J. Pharm. Bioallied Sci. 2011, 3, 496-503. [CrossRef] [PubMed]

6. Stapleton, A.E.; Au-Yeung, M.; Hooton, T.M.; Fredricks, D.N.; Roberts, P.L.; Czaja, C.A.; Yarova-Yarovaya, Y.; Fiedler, T.; Cox, M.; Stamm, W.E. Randomized, placebo-controlled phase 2 trial of a Lactobacillus crispatus probiotic given intravaginally for prevention of recurrent urinary tract infection. Clin. Infect. Dis. 2011, 52, 1212-1217. [CrossRef] 
7. Ghartey, J.P.; Smith, B.C.; Chen, Z.; Buckley, N.; Lo, Y.; Ratner, A.J.; Herold, B.C.; Burk, R.D. Lactobacillus crispatus dominant vaginal microbiome is associated with inhibitory activity of female genital tract secretions against Escherichia coli. PLoS ONE 2014, 9, e96659. [CrossRef]

8. Butler, D.S.C.; Silvestroni, A.; Stapleton, A.E. Cytoprotective effect of Lactobacillus crispatus CTV-05 against uropathogenic E. coli. Pathogens 2016, 5, 27. [CrossRef]

9. Nardini, P.; Nahui Palomino, R.A.; Parolin, C.; Laghi, L.; Foschi, C.; Cevenini, R.; Vitali, B.; Marangoni, A. Lactobacillus crispatus inhibits the infectivity of Chlamydia trachomatis elementary bodies, in vitro study. Sci. Rep. 2016, 6, 29024. [CrossRef] [PubMed]

10. Atassi, F.; Pho Viet Ahn, D.L.; Lievin-Le Moal, V. Diverse expression of antimicrobial activities against bacterial vaginosis and urinary tract Infection pathogens by cervicovaginal microbiota strains of Lactobacillus gasseri and Lactobacillus crispatus. Front. Microbiol. 2019, 10, 2900. [CrossRef]

11. Li, T.; Liu, Z.; Zhang, X.; Chen, X.; Wang, S. Local probiotic Lactobacillus crispatus and Lactobacillus delbrueckii exhibit strong antifungal effects against vulvovaginal candidiasis in a rat model. Front. Microbiol. 2019, 10, 1033. [CrossRef] [PubMed]

12. Charteris, W.P.; Kelly, P.M.; Morelli, L.; Collins, J.K. Antibacterial activity associated with Lactobacillus gasseri ATCC 9857 from the human female genitourinary tract. World J. Microbiol. Biotechnol. 2001, 17, 615-625. [CrossRef]

13. Spurbeck, R.R.; Arvidson, C.G. Lactobacillus jensenii surface-associated proteins inhibit Neisseria gonorrhoeae adherence to epithelial cells. Infect. Immun. 2010, 78, 3103-3111. [CrossRef]

14. Shim, Y.H.; Lee, S.J.; Lee, J.W. Antimicrobial activity of lactobacillus strains against uropathogens. Pediatr. Int. 2016, 58, 1009-1013. [CrossRef]

15. Morais, I.M.C.; Cordeiro, A.L.; Teixeira, G.S.; Domingues, V.S.; Nardi, R.M.D.; Monteiro, A.S.; Alves, R.J.; Siqueira, E.P.; Santos, V.L. Biological and physicochemical properties of biosurfactants produced by Lactobacillus jensenii P6A and Lactobacillus gasseri P65. Microb. Cell Factories 2017, 16, 155. [CrossRef] [PubMed]

16. Kim, J.; Muhammad, N.; Jhun, B.H.; Yoo, J.W. Probiotic delivery systems: A brief overview. J. Pharm. Investig. 2016, 46, 377-386. [CrossRef]

17. Borges, S.; Barbosa, J.; Teixeira, P. Drug delivery systems for vaginal infections. In Frontiers in Clinical Drug Research: Anti-Infectives; Rahman, A.U., Ed.; Bentham Science Publishers: Sharjah, United Arab Emirates, 2015; Volume 2, pp. 233-258. [CrossRef]

18. Torres-Martinez, E.J.; Cornejo Bravo, J.M.; Serrano Medina, A.; Perez Gonzalez, G.L.; Villarreal Gomez, L.J. A summary of electrospun nanofibers as drug delivery system: Drugs loaded and biopolymers used as matrices. Curr. Drug Deliv. 2018, 15, 1360-1374. [CrossRef] [PubMed]

19. Teo, W.E.; Ramakrishna, S. A review on electrospinning design and nanofibre assemblies. Nanotechnology 2006, 17, R89-R106. [CrossRef]

20. Sharma, A.; Pathak, D.; Patil, D.S.; Dhiman, N.; Bhullar, V.; Mahajan, A. Electrospun PVP/TiO2 nanofibers for filtration and possible protection from various viruses like COVID-19. Technologies 2021, 9, 89. [CrossRef]

21. Pathak, D.; Kumar, S.; Andotra, S.; Thomas, J.; Kaur, N.; Kumar, P.; Kumar, V. New tailored organic semiconductors thin films for optoelectronic applications. Eur. Phys. J. Appl. Phys. 2021, 95, 10201. [CrossRef]

22. Sofi, H.S.; Abdal-Hay, A.; Ivanovski, S.; Zhang, Y.S.; Sheikh, F.A. Electrospun nanofibers for the delivery of active drugs through nasal, oral and vaginal mucosa: Current status and future perspectives. Mater. Sci. Eng. C Mater. Biol. Appl. 2020, 111, 110756. [CrossRef] [PubMed]

23. Stojanov, S.; Berlec, A. Electrospun nanofibers as carriers of microorganisms, stem cells, proteins, and nucleic acids in therapeutic and other applications. Front. Bioeng. Biotechnol. 2020, 8, 130. [CrossRef] [PubMed]

24. Heunis, T.D.; Botes, M.; Dicks, L.M. Encapsulation of Lactobacillus plantarum 423 and its bacteriocin in nanofibers. Probiotics Antimicrob. Proteins 2010, 2, 46-51. [CrossRef]

25. Feng, K.; Zhai, M.Y.; Zhang, Y.; Linhardt, R.J.; Zong, M.H.; Li, L.; Wu, H. Improved viability and thermal stability of the probiotics encapsulated in a novel electrospun fiber mat. J. Agric. Food Chem. 2018, 66, 10890-10897. [CrossRef]

26. Luan, Q.; Zhou, W.; Zhang, H.; Bao, Y.; Zheng, M.; Shi, J.; Tang, H.; Huang, F. Cellulose-based composite macrogels from cellulose fiber and cellulose nanofiber as intestine delivery vehicles for probiotics. J. Agric. Food Chem. 2018, 66, 339-345. [CrossRef]

27. Škrlec, K.; Zupančič, S.; Prpar Mihevc, S.; Kocbek, P.; Kristl, J.; Berlec, A. Development of electrospun nanofibers that enable high loading and long-term viability of probiotics. Eur. J. Pharm. Biopharm. 2019, 136, 108-119. [CrossRef] [PubMed]

28. Yu, H.; Liu, W.; Li, D.; Liu, C.; Feng, Z.; Jiang, B. Targeting delivery system for Lactobacillus plantarum based on functionalized electrospun nanofibers. Polymers 2020,12, 1565. [CrossRef]

29. Fung, W.Y.; Yuen, K.H.; Liong, M.T. Agrowaste-based nanofibers as a probiotic encapsulant: Fabrication and characterization. J. Agric. Food Chem. 2011, 59, 8140-8147. [CrossRef]

30. Ceylan, Z.; Meral, R.; Karakaş, C.Y.; Dertli, E.; Yilmaz, M.T. A novel strategy for probiotic bacteria: Ensuring microbial stability of fish fillets using characterized probiotic bacteria-loaded nanofibers. Innov. Food Sci. Emerg. Technol. 2018, 48, 212-218. [CrossRef]

31. Amna, T.; Hassan, M.S.; Pandeya, D.R.; Khil, M.S.; Hwang, I.H. Classy non-wovens based on animate L. gasseri-inanimate poly(vinyl alcohol): Upstream application in food engineering. Appl. Microbiol. Biotechnol. 2013, 97, 4523-4531. [CrossRef]

32. Soares, J.M.D.; Abreu, R.E.F.; da Costa, M.M.; de Oliveira, H.P. Investigation of Lactobacillus paracasei encapsulation in electrospun fibers of Eudragit ${ }^{\circledR}$ L100. Polimeros 2020, 30, e2020025. [CrossRef]

33. Zupančič, S.; Škrlec, K.; Kocbek, P.; Kristl, J.; Berlec, A. Effects of electrospinning on the viability of ten species of lactic acid bacteria in poly(ethylene oxide) nanofibers. Pharmaceutics 2019, 11, 483. [CrossRef] 
34. Silva, J.A.; De Gregorio, P.R.; Rivero, G.; Abraham, G.A.; Nader-Macias, M.E.F. Immobilization of vaginal Lactobacillus in polymeric nanofibers for its incorporation in vaginal probiotic products. Eur. J. Pharm. Sci. 2021, 156, 105563. [CrossRef]

35. Nagy, Z.K.; Wagner, I.; Suhajda, A.; Tobak, T.; Harasztos, A.H.; Vigh, T.; Sóti, P.L.; Pataki, H.; Molnar, K.; Marosi, G. Nanofibrous solid dosage form of living bacteria preparedby electrospinning. Express Polym. Lett. 2014, 8, 352-361. [CrossRef]

36. Herbel, S.R.; Vahjen, W.; Wieler, L.H.; Guenther, S. Timely approaches to identify probiotic species of the genus Lactobacillus. Gut Pathog. 2013, 5, 27. [CrossRef] [PubMed]

37. Welch, J.L.M.; Hasegawa, Y.; McNulty, N.P.; Gordon, J.I.; Borisy, G.G. Spatial organization of a model 15-member human gut microbiota established in gnotobiotic mice. Proc. Natl. Acad. Sci. USA 2017, 114, E9105-E9114. [CrossRef] [PubMed]

38. Yu, Q.H.; Dong, S.M.; Zhu, W.Y.; Yang, Q. Use of green fluorescent protein to monitor Lactobacillus in the gastro-intestinal tract of chicken. FEMS Microbiol. Lett. 2007, 275, 207-213. [CrossRef] [PubMed]

39. Berlec, A.; Završnik, J.; Butinar, M.; Turk, B.; Štrukelj, B. In vivo imaging of Lactococcus lactis, Lactobacillus plantarum and Escherichia coli expressing infrared fluorescent protein in mice. Microb. Cell Factories 2015, 14, 181. [CrossRef]

40. Han, X.; Wang, L.; Li, W.; Li, B.; Yang, Y.; Yan, H.; Qu, L.; Chen, Y. Use of green fluorescent protein to monitor Lactobacillus plantarum in the gastrointestinal tract of goats. Braz. J. Microbiol. 2015, 46, 849-854. [CrossRef]

41. Karimi, S.; Ahl, D.; Vagesjo, E.; Holm, L.; Phillipson, M.; Jonsson, H.; Roos, S. In vivo and in vitro detection of luminescent and fluorescent Lactobacillus reuteri and application of red fluorescent mCherry for assessing plasmid persistence. PLoS ONE 2016, 11, e0151969. [CrossRef]

42. Spacova, I.; Lievens, E.; Verhoeven, T.; Steenackers, H.; Vanderleyden, J.; Lebeer, S.; Petrova, M.I. Expression of fluorescent proteins in Lactobacillus rhamnosus to study host-microbe and microbe-microbe interactions. Microb. Biotechnol. 2018, 11, 317-331. [CrossRef]

43. Tsuji, F.I. Oxidation of a cyclic tripeptide by molecular oxygen and the development of fluorescence in the Aequorea green fluorescent protein. Int. Congr. Ser. 2002, 1233, 37-44. [CrossRef]

44. Stephenson, D.P.; Moore, R.J.; Allison, G.E. Transformation of, and heterologous protein expression in, Lactobacillus agilis and Lactobacillus vaginalis isolates from the chicken gastrointestinal tract. Appl. Environ. Microbiol. 2011, 77, 220-228. [CrossRef]

45. Berthier, F.; Zagorec, M.; Champomier-Vergès, M.; Ehrlich, S.D.; Morel-Deville, F. Efficient transformation of Lactobacillus sake by electroporation. Microbiol. Soc. 1996, 142, 1273-1279. [CrossRef]

46. Beasley, S.S.; Takala, T.M.; Reunanen, J.; Apajalahti, J.; Saris, P.E. Characterization and electrotransformation of Lactobacillus crispatus isolated from chicken crop and intestine. Poult. Sci. 2004, 83, 45-48. [CrossRef] [PubMed]

47. Allain, T.; Mansour, N.M.; Bahr, M.M.; Martin, R.; Florent, I.; Langella, P.; Bermudez-Humaran, L.G. A new lactobacilli in vivo expression system for the production and delivery of heterologous proteins at mucosal surfaces. FEMS Microbiol. Lett. 2016, 363, fnw117. [CrossRef]

48. Talwalkar, A.; Kailasapathy, K. The role of oxygen in the viability of probiotic bacteria with reference to L. acidophilus and Bifidobacterium spp. Curr. Issues Intest. Microbiol. 2004, 5, 1-8.

49. Gupta, P.K.; McGrath, C. Microbiology, inflammation, and viral infections. In Comprehensive Cytopathology, 3rd ed.; Bibbo, M., Wilbur, D., Eds.; Elsevier Inc.: Amsterdam, The Netherlands, 2008; pp. 91-129. [CrossRef]

50. Nader-Macias, M.E.; Juarez Tomas, M.S. Profiles and technological requirements of urogenital probiotics. Adv. Drug Deliv. Rev. 2015, 92, 84-104. [CrossRef]

51. Kadkhodaei, S.; Memari, H.R.; Abbasiliasi, S.; Rezaei, M.A.; Movahedi, A.; Shun, T.J.; Ariff, A.B. Multiple overlap extension PCR (MOE-PCR): An effective technical shortcut to high throughput synthetic biology. RSC Adv. 2016, 6, 66682-66694. [CrossRef]

52. Salome-Desnoulez, S.; Poiretb, S.; Foligne, B.; Muharram, G.; Peucelle, V.; Lafont, F.; Daniel, C. Persistence and dynamics of fluorescent Lactobacillus plantarum in the healthy versus inflamed gut. Gut Microbes 2021, 13, 1-16. [CrossRef] [PubMed]

53. Tauer, C.; Heinl, S.; Egger, E.; Heiss, S.; Grabherr, R. Tuning constitutive recombinant gene expression in Lactobacillus plantarum. Microb. Cell. Factories 2014, 13, 150. [CrossRef] [PubMed]

54. Subach, O.M.; Cranfill, P.J.; Davidson, M.W.; Verkhusha, V.V. An enhanced monomeric blue fluorescent protein with the high chemical stability of the chromophore. PLOS ONE 2011, 6, e28674. [CrossRef] [PubMed]

55. Mierau, I.; Kleerebezem, M. 10 years of the nisin-controlled gene expression system (NICE) in Lactococcus lactis. Appl. Microbiol. Biotechnol. 2005, 68, 705-717. [CrossRef] [PubMed] 